\title{
Students perceived stress in academic programs: Consequences for its management
}

\author{
Stress perçu dans les filières universitaires : implications pour sa gestion

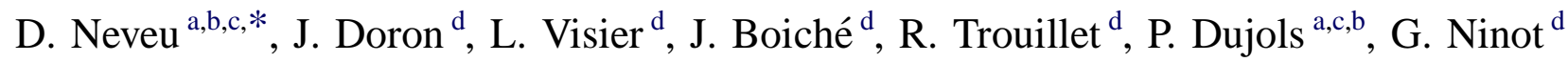 \\ ${ }^{a}$ Université Montpellier-1, 34090 Montpellier, France \\ ${ }^{\mathrm{b}}$ Inserm U 1058, 34394 Montpellier, France \\ ${ }^{\mathrm{c}}$ Département de l'information médicale, pavillon 1, hôpital la Colombière, CHU de Montpellier, \\ 39, avenue Charles-Flahault, 34295 Montpellier cedex 5, France \\ ${ }^{\mathrm{d}}$ EA 4556 dynamique des capacités humaines et des conduites de santé, laboratoire Epsylon, université Montpellier-1, 34000 Montpellier, France
}

\section{Abstract}

Background. - Academic stress contributes to the deterioration of the students' quality of life. Psychological determinants involved in the stress process, trait anxiety and coping, have been neglected when assessing the role of academic programs in stress. This study aimed at determining whether academic programs are associated with a high level of perceived stress above and beyond potential personal and environmental risk factors, as well as coping strategies.

Methods. - A cross-sectional survey was conducted in 2009 among third-year medical (total $n=170$, participants 88\%), dental $(n=63,94 \%)$, psychology $(n=331,61 \%)$ and sports sciences $(n=312,55 \%)$ students in Montpellier (France). The stress level experienced during the last 2 months, trait anxiety and coping strategies were appraised. Substance use, psychological care, and stress triggers were also collected using a selfadministered questionnaire.

Results. - Compared with medicine and after adjusting for gender and age, only the sports program was associated with a lower perceived stress risk: adjusted odds ratio: 0.54 [95\% Confidence interval: 0.30; 0.99]. Substantial reductions in perceived stress risks were observed in science students after additional adjustments for non-academic stress triggers, substance use, psychological care (adjusted odds ratio: 0.20 [95\% Confidence interval: 0.09; 0.41]), and also for trait anxiety and coping strategies (adjusted odds ratio: 0.23 [95\% Confidence interval: 0.10; 0.54]). Compared with medicine and after these additional adjustments, psychology had a significantly lower perceived stress risk (0.34 [0.18; 0.64$] ; 0.40$ [0.19;0.86], respectively), dentistry had a similar risk $(0.82[0.35 ; 1.91] ; 0.53[0.20 ; 1.43]$, respectively).

Conclusion. - Sports and psychology programs had a lower perceived stress risk compared with medicine. Personal and environmental risk factors and coping strategies modified the association between academic program and perceived stress. Developing efficient coping strategies in students and improving academic environment could contribute to prevent the potential deleterious consequences of stress.

Keywords: Perceived stress; Undergraduate curriculum; Coping behaviour; Education

Résumé

Position du problème. - Le stress académique contribue à détériorer la qualité de vie des étudiants. La prédisposition à l'anxiété et les stratégies de coping, facteurs impliqués dans le stress, sont négligées dans l'étude du rôle du cursus universitaire sur le stress. Cette étude a analysé le rôle de la filière académique comme facteur de risque de stress perçu élevé après prise en compte des facteurs de risque personnels, environnementaux et des stratégies de coping.

Méthodes. - Enquête transversale menée chez des étudiants inscrits en troisième année à Montpellier en 2009-2010 : médecine, 170 (participants : $88 \%$ ) ; odontologie, 63 (94\%) ; psychologie, $331(61 \%)$; sports, $312(55 \%)$. Le niveau de stress perçu pendant les deux derniers

\footnotetext{
* Corresponding author.

E-mail address: d-neveu@chu-montpellier.fr (D. Neveu).
} 
mois, la prédisposition à l'anxiété et les stratégies de coping ont été évalués. Consommation de substances, suivi psychologique et sources de stress étaient aussi recueillis par auto-questionnaire.

Résultats. - Seule la filière sports avait un risque de stress perçu significativement moindre par rapport à la médecine après ajustement sur l'âge et le genre (Odds Ratio ${ }_{a j u s t e ́ ~}: 0,54$ [intervalle de confiance à $\left.\left.95 \%: 0,30 ; 0,99\right]\right)$. Ce risque était réduit après ajustements complémentaires sur les facteurs environnementaux non académiques, les consommations de substances, un suivi psychologique $(0,20$ [0,09;0,41]) ainsi que sur l'anxiété et les stratégies de coping $(0,23[0,10 ; 0,54])$. Comparée à la médecine, la filière psychologie avait un risque moindre de stress perçu après ces mêmes ajustements $(0,34[0,18 ; 0,64] ; 0,40[0,19 ; 0,86]$, respectivement), et la filière odontologie avait un risque semblable $(0,82[0,35 ; 1,91]$; $0,53[0,20 ; 1,43]$, respectivement).

Conclusion. - Les filières sports et psychologie auraient un risque moindre de stress perçu par rapport à la filière médecine. L'association entre filière et stress perçu est influencée par les facteurs de risque personnels, environnementaux et les stratégies de coping. Développer des stratégies de coping efficaces et améliorer le cadre académique contribueraient à prévenir les conséquences délétères du stress.

Mots clés : Stress perçu ; Filière universitaire ; Gestion du stress ; Étudiants ; Éducation

Undergraduate students experience the transition from adolescence to adulthood, as well as massive socio-economic changes and increasing academic competition. Within this population, stress is a critical issue: most students (52 to 75\%) report an intermediate or a high level of stress [1-4] which may impair health [2,5-8]. Academic stress contributes to the deterioration of the students' quality of life and causes drug abuse and academic failure [4,9-14].

Academic programs are viewed as not equally demanding and may be associated with different levels of stress. The medical program is viewed as a stressful environment [15]. However, few studies have compared academic programs and even some failed to confirm this statement [16,17]. The discrepancy in results has been explained by the instruments used to measure stress, some of which were not validated $[16,17]$. However, it also may come from neglected factors influencing stress. Academic stress must then be investigated in the context of other influences of stress in order to identify the academic program(s) at risk, stress risk factors and protective factors with the aim of acting upon them if possible and to decrease stress and its deleterious consequences.

Student psychological and behavioural characteristics play a key role in the stress process. Indeed, referring to the transactional stress and coping model developed by Lazarus and Folkman, perceived stress is the result of the cognitive evaluation of events in the context of the various resources people have $[18,19]$. Coping strategies, i.e., the individual cognitive and behavioural efforts to manage the internal and external demands encountered during a stressful situation, are personal psychological determinants of perceived stress. They are considered as mediators of the relationship between antecedent variables and health [19], explaining how antecedent variables (including the context) predict health-related outcomes. Some may counteract the effects of stress while others may worsen them. Problem-solving coping strategies (i.e. problem-focused categories of instrumental action, strategizing and problem-solving) have been associated with a better health and reduced negative affects; cognitive restructuring (i.e. active attempts to view the stressful event as harmless) and support-seeking (i.e. supports such as instrumental help, advice, comfort, or contact sought from parents, peers, or professionals) with a better well-being
[20-22]. These coping strategies are viewed as adaptive in contrast to avoidance coping strategies (i.e. efforts to disengage or stay away from the stressful situation) or to distraction strategies (i.e. focusing away from the stress) [23]. Anxiety trait is another key personal psychological determinant of perceived stress $[18,19]$. Trait anxiety interacts with the internal and external demands encountered during a stressful situation. The higher the anxiety trait level, the more a stressful situation promotes stress [24]. Environmental non-academic stress triggers that students face, i.e. daily hassles, finances, social relationships, personal life issues, also influence stress $[11,16,25]$ and should be investigated.

Based on the transactional stress and coping model [19] and using a well-validated instrument to measure perceived stress [26], this study aimed at determining whether academic programs (medicine, dentistry, psychology and sports sciences) are associated with a high perceived stress level above and beyond potential personal and environmental risk factors, as well as coping strategies. The secondary objective was to investigate whether the academic programs are associated with different coping and vulnerability profiles. We focused on the factors associated with a high perceived stress level and explored the role of coping strategies as mediators of the relationship between academic programs and perceived stress.

\section{Methods}

\subsection{Study design and population}

A cross-sectional survey was conducted between midNovember and mid-December 2009 in Montpellier (France), among the third-year students who enrolled in one of the following programs: medicine $(n=170)$, dentistry $(n=63)$, psychology $(n=331)$ and sports sciences $(n=312)$. Students were given information about the survey and completed a consent form with an anonymous questionnaire during a compulsory class. The questionnaire was pilot tested with ten students. The protocol was also approved by an ethical committee, the Comité de Protection des Personnes SUD Méditerranée IV.

In order to determine whether participants were representative of their year regarding gender and age, data was 
anonymously collected for all students at the enrolment office of each faculty.

\subsection{Measures}

\subsubsection{Socio-economic data}

Current sociodemographic data (age: ::; 20; 21-22; 23-27;

$\therefore 28$ years), employment (yes/no; if employed; regular; occasional), involvement in associations (yes/no) were collected.

\subsubsection{Trait anxiety}

A validated French version of the State-Trait Anxiety Inventory trait form (STAI-Y) was used. This inventory has 20 items with answers ranked on a 4-point scale from 'almost never' to 'almost always' and assesses trait anxiety [27]. STAIY Trait score ranged from 20 to 80 with higher scores indicating greater trait anxiety. The inventory showed a good internal consistency: Cronbach's alpha coefficient $=0.89$. Trait anxiety was categorized according to $\mathrm{T}$ values based on STAI-Y-Trait scores and gender standardisation, with 'high' ( $\mathrm{T}$ value $>55$ ), 'moderate' (T value, 46 to 55), 'slight' (T value < 46) [28].

\subsubsection{Perceived stress}

A French version of the Perceived Stress Scale with 14 items (PSS-14) was used. This instrument has 14 questions with answers ranked on a 5-point scale from 'never' to 'very often' and assessed stressful experiences and responses to stress over the last 2 months [26,29]. PSS-14 scores from 0 to 56 with higher scores indicating higher perceived stress. The internal consistency was satisfactory: $a=0.86$.

Like perceived stress, we assessed stress triggers and substance use over the last 2 months and the coping strategies used to face these sources of stress.

\subsubsection{Stress triggers}

Life and education related stressor events known as stressors in students [1,30,31] were collected with the question: "Here are some sources of stress. Read each proposition, then, on the 6-point scale on the right-hand side, tick the cell which best describes your situation during the last 2 months." The propositions were "family", "interaction with peers", "love life", "moral isolation", "personal financial difficulties", "'personal health problems", "'addiction", “'anxiety about the future", "exams", “continuous assessment", “clerkship or placement", "workload". Each factor was ranked on a 6-point scale according to its intensity from 0 (not a stressor) to 5 (major stressor). Sources of stress were categorized as slight (scores from 0 to 2 ) or intense (from 3 to 5 ).

\subsubsection{Coping strategies}

The strategies used to cope with the sources of stress were assessed with a validated French version of the Brief Cope $[32,33]$. This instrument has 28 items with answers ranked on a 4-point scale from 1 'Not at all' to 4 'Always', and measures 14 scales of coping, of two items each. The internal consistency of each Brief Cope scale was satisfactory (planning: $a=0.71$; active coping: 0.55 ; humour: 0.82 ; positive reframing: 0.70 ; acceptance: 0.75 ; instrumental support: 0.87 ; emotional support: 0.80; denial: 0.68; self-blame: 0.67 ; substance use:

0.91 ; behavioural disengagement: 0.60 ; religion: 0.89 ; venting: $0.76)$, except for the self-distraction scale $(a=0.18)$. For these scales, a minimal $a$ value of 0.50 is regarded acceptable [32].

Five higher dimensions of coping were extracted in agreement with the recently validated measurement model of the BriefCope (Psychological Assessment, in revision). They included problem-solving (active coping, planning), cognitive restructuring (acceptance, humour, positive reframing), support-seeking (emotional support, instrumental support, religion), avoidance (behavioural disengagement, denial, self-blame, substance use) and distraction (self-distraction, venting). Each Brief Cope scale was scored by summing the scores of its two constitutive items [32,33], and each higher-order coping dimension was measured by the mean of its components scores. We further refer to them as coping strategies.

\subsubsection{Health-related behaviours}

Regular exercise (< $1 \mathrm{~h}$ /week; 1 to $3 \mathrm{~h} /$ week; $>3 \mathrm{~h} /$ week) was collected and substance use was assessed based on the frequency of:

- coffee consumption ( $>3$ cups a day, between 1 and 3 cups a day, No);

- alcohol consumption (every day, 3 to 4 times/week, 1 to 2 times/week, 2 to 3 times/month, less often, never);

- tobacco consumption (> 30 cigarettes per day, between 21 and 30 cigarettes per day, between 11 and 20 cigarettes per day, between 1 to 10 cigarettes per day, No);

- marijuana use (every day, regularly, from time to time, has tried, has stopped, never);

- mood regulating medicines, psychostimulant, over-thecounter stimulant, tranquillizer, antidepressant, and hypnotic (each was graded on a 4-point Likert scale: never, sometimes, often, every day).

The choice of these substances came from studies dedicated to substance use behaviors in students $[34,35]$.

Students were also asked to report whether they had consulted a psychologist/psychiatrist since entering university. Psychological care was defined as tranquillizer, antidepressant or hypnotic use or consulting a psychologist/psychiatrist.

\subsection{Statistical analyses}

The four academic programs were compared with the Pearson $\mathrm{Chi}^{2}$ test for qualitative parameters and with the Kruskall-Wallis test for quantitative scores. Closed test procedures (Holm-Bonferroni and step-down bootstrap) were used for two by two comparisons between the four academic programs in order to control the family-wise error rate at $5 \%$ (SAS procedure multtest). The Fisher exact test or Pearson $\mathrm{Chi}^{2}$ test were used for qualitative parameters and the $t$-test or Wilcoxon tests for quantitative parameters. To determine the factors associated with perceived stress, PSS-14 scores 
(PSS-14 scores :'. 31 - upper quartile estimated in the whole sample) were dichotomized since their distribution was not gaussian. Although PSS-14 is not a diagnostic scale [26], PSS-14 :'. 31 was reported as a perceived stress in the present article.

To estimate the perceived stress risk associated with the academic program, multivariate logistic regression models were built using a step-wise procedure. The medicine program was the reference level because of a large sample size and sexratio almost equal to 1 . Multivariate logistic regression models included any factor associated with PSS-14 :'. 31 after adjusting for gender and age: the significance level was $P<0.3$ for entering variables and $P: 1.0 .05$ for removing variables, except for age and gender which were included in all models. The age was dichotomized: less or equal to 20 years versus more than 20 years. The 20-year-old threshold accounted for a French standard education without repeating a year.

Several multivariate logistic models were built with the following covariates:

- model 1: gender, age (::; 20 versus > 20 years), academic program, socio-economic and non-academic environmental factors, substance use and psychological care;

- model 2: the same covariates as in model 1, with the addition of coping strategies and trait anxiety;

- model 3: the same covariates as in model 1, with the addition of academic stress triggers;

- model 4: the same covariates as in model 3, with the addition of coping strategies and trait anxiety.

Their quality of adjustment was tested with the Hosmer and Lemeshow's statistic. Although not directly related to the objectives of the study, models 3 and 4 complement models 1 and 2 by giving an insight about aspects of the academic programs that would lead to stress.

To assess the impact of risk factors adjustment of model 1 on the gender-age-adjusted relative risk, roughly estimated by the gender-age-adjusted odds ratio (OR), the proportion of excess relative risk accounted for by covariates adjustment was calculated as:

$$
\begin{aligned}
& \text { ORðgender-age-ad justed } \mathrm{P}-\text { ORðadjusted for model } 1 \text { covariates } \mathrm{P}= \\
& \text { OR } R_{\text {gender-age-adjusted } \mathrm{P}}-1
\end{aligned}
$$

where positive values indicate reduction in ORs and negative values, increases in ORs, if OR $>1$. Opposite interpretations are driven if $\mathrm{OR}<1$ [36].

In agreement with the transactional stress and coping model [19], we also tested whether academic programs had an indirect effect on a perceived stress mediated by coping strategies in simple mediation models. A mediator is defined as "a variable transmitting the effect of an independent variable on a dependent variable" [37]. Whether or not a mediation occurs can be determined by testing the independent variable's (IV) indirect effect through one or more mediators (Mi) on the dependent variable (DV). A mediating effect was evidenced by showing a statistically significant increase in the beta estimate of the path between IV and DV when Mi was excluded (i.e., the total effect of IVon DV) in comparison with the beta estimate of the same path when Mi was included (i.e., the direct effect of IV on DV). Here, the academic program was the independent variable, a perceived stress, the dependent variable, a coping strategy, the mediator. Total effects of academic programs on a perceived stress were estimated with logistic regression models with the following form: Logit (perceived stress $)=b_{0}+\left(b_{1} \mathrm{x}\right.$ academic program $)+\left(b_{2 \mathrm{i}} \times \mathrm{i}\right.$ adjustment factors $)$. Direct effects were estimated with models with the following form: Logit (perceived stress $)=b^{\prime}{ }_{0}+\left(b^{\prime}{ }_{1} \times\right.$ academic program $)+$ $\left(b^{\prime}{ }_{2 \mathrm{i}} \times \mathrm{i}\right.$ adjustment factors $)+\left(b_{3}^{\prime} \times\right.$ coping strategy $)$. Adjustment factors were gender, age, trait anxiety, sources of intense stress, family, personal difficulties, anxiety about the future, factors significantly associated with a perceived stress in model

2. Mediation of a coping strategy was tested through percentilebased bootstrap confidence interval of indirect effects ( 2.5 and 97.5 percentiles) estimated with 2000 bootstrap samples $[38,39]$.

Interactions between academic program and gender, trait anxiety, or coping strategies significantly associated with perceived stress in model 2 were tested.

Statistical significance was set at 5\%. Analyses were carried out with $\mathrm{SAS}^{1}$ (version 9.1; SAS Institute Inc, Cary, NC, USA).

\section{Results}

Five hundred and eighty-two students $(66.5 \%$ of the target population) took part in the study: medicine: 149 (88\%), dentistry: 59 (94\%), psychology: 201 (61\%) and sports: 173 $(55 \%)$. Their sociodemographic characteristics are reported in Table 1 as well as trait anxiety and PSS-14 scores. Participants were representative of their year with respect to gender (medicine: $58 \%$ female vs $58 \%, P=0.98$; dentistry: $52 \%$ female vs $54 \%, P=0.8$; psychology: $86 \%$ female vs $81 \%$, $P=0.098$; sports: $33 \%$ female vs $31 \%, P=0.8$ ) and age distribution (medicine, $P=0.53$; dentistry, $P=0.88$; psychology, $P=0.11$; sports, $P=0.17$ ).

Only the sports program had a significantly lower perceived stress risk in comparison with medicine after adjustment for gender and age $\left(\mathrm{OR}_{\text {(gender-age-adjusted) }}=0.54\right.$, 95\% confidence interval [0.30-0.99], Table 2). Female gender, a high or a moderate trait anxiety, tobacco use, psychological care, avoidance coping strategies, and the non-academic stressors, family, interaction with peers, love life, moral isolation, personal financial difficulties, personal health problems, addiction, anxiety about the future were perceived stress risk factors $\left(\mathrm{OR}_{\text {(gender-age-adjusted) }}>1\right.$ with $P<0.05$, Table 2$)$. In contrast, problem-solving and cognitive restructuring coping strategies were protective factors $\left(\mathrm{OR}_{\text {(gender-age-adjusted) }}<1\right.$ with $P<0.05$, Table 2).

Model 1 and model 2 additional adjustments for socioeconomic and non-academic environmental factors, substance use, psychological care, trait anxiety and coping strategies revealed that psychology had a significantly lower perceived 
Table 1

Characteristics of third-year undergraduate students in their respective academic program.

\begin{tabular}{|c|c|c|c|c|c|c|}
\hline & Total sample & Faculty Medicine & Faculty Dentistry & Faculty Psychology & Faculty Sports & $P$-value ${ }^{\mathrm{a}}$ \\
\hline Female gender, n (\%) & $343(60)$ & $87(58)$ & $30(52)$ & $170(86)$ & $56(33)$ & $<0.001$ \\
\hline Age, n (\%) & & & & & & $<0.001$ \\
\hline ::;20 years & $161(28)$ & $45(30)$ & $15(25)$ & $47(23)$ & $54(31)$ & \\
\hline $21-22$ years & $304(52)$ & $92(62)$ & $40(68)$ & $95(47)$ & $77(45)$ & \\
\hline$\therefore 23$ years & $116(20)$ & $12(8)$ & $4(7)$ & $59(30)$ & $41(24)$ & \\
\hline Employment, n (\%) & $159(28)$ & $37(25)$ & $11(19)$ & $52(26)$ & $59(35)$ & 0.050 \\
\hline Regular employment, $n(\%)$ & $99(60)$ & $10(27)$ & $8(73)$ & $41(79)$ & $40(68)$ & $<0.001$ \\
\hline Involvement in associations, $\mathrm{n}(\%)$ & $245(42)$ & $62(42)$ & $18(31)$ & $50(25)$ & $115(67)$ & $<0.001$ \\
\hline$\therefore 30$ minutes commutation, $\mathrm{n}(\%)$ & $224(39)$ & $55(37)$ & $22(37)$ & $88(44)$ & $59(34)$ & 0.26 \\
\hline Regular exercise, n (\%) & & & & & & $<0.001$ \\
\hline$<1$ h per week & $175(30)$ & $52(35)$ & $30(51)$ & $90(45)$ & $3(2)$ & \\
\hline $1-3 \mathrm{~h}$ per week & $187(32)$ & $76(51)$ & $20(34)$ & $77(38)$ & $14(8)$ & \\
\hline$>3 \mathrm{~h}$ per week & $220(38)$ & $21(14)$ & $9(15)$ & $34(17)$ & $156(90)$ & \\
\hline STAI-Y Trait score, median $[Q 1-Q 3]$ & 43 [37-51] & $44[37-51]$ & $45[37-52]$ & $47[41-54]$ & $39[35-46]$ & $<0.001$ \\
\hline Trait anxiety, n (\%) & & & & & & $<0.001$ \\
\hline High $(\mathrm{T}>55)$ & $174(31)$ & $40(30)$ & $19(33)$ & $79(40)$ & $36(22)$ & \\
\hline Moderate (T: 46-55) & $195(35)$ & $52(38)$ & $22(39)$ & $69(35)$ & $52(31)$ & \\
\hline Slight $(\mathrm{T}<46)$ & $186(34)$ & $43(32)$ & $16(28)$ & $50(25)$ & $77(47)$ & \\
\hline$P S S-14$ score, median [Q1-Q3] & $25[19-31]$ & $26[19-31]$ & 25 [19-33] & $27[22-33]$ & $21[17-27]$ & $<0.001$ \\
\hline PSS-14 score (:'. 31), n (\%) & & $39(27)$ & $17(29)$ & $66(33.5)$ & $23(14)$ & $<0.001$ \\
\hline
\end{tabular}

PSS: perceived stress scale. PSS-14 scores, from 0 to 56 increase with increased levels of perceived stress [26,29]; Q1: lower quartile; Q3: upper quartile.

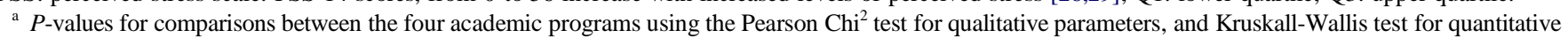
scores.

stress risk in comparison with medicine $\left(\mathrm{OR}_{(\text {adjusted for model } 1}\right.$ covariates $)=0.34,95 \%$ confidence interval $[0.18-0.64] ; \mathrm{OR}_{(\mathrm{ad}-}$ justed for model 2 covariates) $=0.40,95 \%$ confidence interval $[0.19-$ 0.86], Table 2). Model 1 adjustment reduced the gender-ageadjusted odds ratio in sports program by $74 \%$ (Table 2). Compared with medicine, dentistry had a similar risk. The stressors, family, personal financial difficulties, anxiety about the future, were perceived stress risk factors in both models 1 and 2 while psychological care, interaction with peer, and love life were risk factors only in model 1. A high or a moderate trait anxiety was a strong stress risk factor (model 2). Avoidance coping strategies were stress risk factors while problem-solving coping strategies were protective. There was no statistically significant indirect effect of academic programs on perceived stress mediated by a coping strategy (Table 3), and no significant interaction between the academic program, and gender, trait anxiety, problem-solving or avoidance coping strategies.

Additional adjustments for academic stress triggers in model 3 revealed that sports and psychology had a significantly lower perceived stress risks than medicine: sports, $\mathrm{OR}_{\text {(adjusted for model }}$ 3 covariates) $=0.26,95 \%$ confidence interval $[0.12 ; 0.55]$; psychology, $\mathrm{OR}_{\text {(adjusted for model } 3 \text { covariates) }}=0.38, \quad 95 \%$ confidence interval $[0.20 ; 0.73]$. Dentistry had no significantly lower risk compared with medicine. In contrast, when coping strategies and trait anxiety were also adjusted for in model 4, no program was different from medicine. Family, anxiety about the future and workload were risk factors in both models 3 and 4 while psychological care, interaction with peers, moral isolation, personal financial difficulties, exams were risk factors only in model 3. A moderate or a severe trait anxiety and avoidance coping strategies were risk factors in model 4 while problem-solving coping strategies were a protective factor (data not shown, available on request).

As shown in Tables 1 and 4 and Figs. 1 and 2, academic programs were associated with different coping and vulnerability profiles. Medical and dental students were younger compared with psychology and sports students and most students were women in medicine, dentistry and psychology in contrast to the sports program. The factors significantly associated with perceived stress after gender-age adjustment which significantly varied between the academic programs were: trait anxiety, family, love life, moral isolation, personal financial difficulties, personal health problems, anxiety about the future, exams, continuous assessment, clerkship or placement, workload, psychological care, tobacco use and problem-solving coping strategies. Regarding these factors, we carried out two by two comparisons between the academic programs in order to identify which programs had more risk factors or protective factors. Significantly more psychology students reported the following stress risk factors: a high trait anxiety (vs sports, medicine or dentistry), family (vs sports), love life (vs sports or medicine), moral isolation (vs sports or medicine), personal financial difficulties (vs sports, medicine or dentistry), personal health problems (vs medicine), anxiety about the future (vs sports, medicine or dentistry), exams (vs sports), continuous assessment (vs sports, medicine or dentistry), clerkship or placement (vs dentistry), workload (vs sports), a psychological care (vs sports or medicine), and tobacco use (vs sports or medicine). However they developed the most problem-solving strategies. Significantly fewer medicine and/or dentistry students had the following stress risk factors: personal financial difficulties (medicine vs sports), anxiety about the future (medicine or dentistry vs sports), 
Table 2

Factors associated with a perceived stress (PSS-14 score :'. 31) in third-year undergraduate students (582 students).

\begin{tabular}{|c|c|c|c|c|c|c|}
\hline & \multicolumn{2}{|c|}{ Gender-age adju sted } & \multirow{2}{*}{$\begin{array}{l}\text { Model } 1 \\
\text { Adjusted OR }\end{array}$} & \multirow[b]{2}{*}{$95 \% \mathrm{CI}$} & \multicolumn{2}{|l|}{ Model 2} \\
\hline & Adjusted OR & $95 \% \mathrm{CI}$ & & & Adjusted OR & $95 \% \mathrm{CI}$ \\
\hline Gender (female versus male) & $3.42 * * *$ & $2.17-5.37$ & $1.83^{*}$ & $1.05-3.20$ & 1.70 & $0.86-3.38$ \\
\hline Age $(:: ; 20$ versus $>20$ years $)$ & 0.82 & $0.53-1.26$ & 1.09 & $0.66-1.82$ & 1.12 & $0.62-2.03$ \\
\hline Commutation $(<30$ versus :'. $30 \mathrm{~min} / \mathrm{d})$ & 1.22 & $0.81-1.83$ & & & & \\
\hline Employment (no versus yes) & 0.84 & $0.54-1.29$ & & & & \\
\hline Involvement in association (no versus yes) & 0.85 & $0.56-1.30$ & & & & \\
\hline \multicolumn{7}{|l|}{ Academic program } \\
\hline Dentistry versus medicine & 1.10 & $0.55-2.22$ & 0.82 & $0.35-1.91$ & 0.53 & $0.20-1.43$ \\
\hline Psychology versus medicine & 1.04 & $0.63-1.70$ & $0.34 * * *$ & $0.18-0.64$ & $0.40 *$ & $0.19-0.86$ \\
\hline Sports versus medicine & $0.54 *$ & $0.30-0.99$ & $0.20 * * *$ & $0.09-0.41$ & $0.23 * * *$ & $0.10-0.54$ \\
\hline \multicolumn{7}{|l|}{ Non-academic stress triggers (intense versus slight) } \\
\hline Family & $2.49 * * *$ & $1.66-3.73$ & $1.84 * *$ & $1.16-2.91$ & $2.09 * *$ & $1.22-3.56$ \\
\hline Interaction with peers & $3.02 * * *$ & $1.97-4.64$ & $2.62 * * *$ & $1.62-4.24$ & & \\
\hline Love life & $2.47 * * *$ & $1.65-3.69$ & $1.67 *$ & $1.05-2.67$ & & \\
\hline Moral isolation & $2.47 * * *$ & $1.65-3.71$ & & & & \\
\hline Personal financial difficulties & $2.33 * * *$ & $1.56-3.47$ & $1.99 * *$ & $1.24-3.20$ & $1.96^{*}$ & $1.13-3.38$ \\
\hline Personal health problems & $2.07 * *$ & $1.33-3.21$ & & & & \\
\hline Addiction & $2.37 * *$ & $1.38-4.08$ & & & & \\
\hline Anxiety about the future & $4.47 * * *$ & $2.72-7.33$ & $4.23 * * *$ & $2.32-7.71$ & $3.49 * * *$ & $1.69-7.22$ \\
\hline Regular exercise (::; 3 versus > 3 h/week) & 1.47 & $0.92-2.34$ & & & & \\
\hline Coffee use (no versus yes) & 0.88 & $0.58-1.33$ & & & & \\
\hline Alcohol (<once/week versus :'. once/week) & 1.02 & $0.68-1.53$ & & & & \\
\hline Tobacco (no versus yes) & $0.50 * * *$ & $0.34-0.75$ & & & & \\
\hline Marijuana (never versus past or current use) & 0.70 & $0.47-1.04$ & & & & \\
\hline Psychological care (yes versus no) & $2.63 * * *$ & $1.70-4.06$ & $2.21 * *$ & $1.36-3.59$ & & \\
\hline \multicolumn{7}{|l|}{ Coping strategies (per additional unit) } \\
\hline Problem-solving & $0.72 * * *$ & $0.61-0.84$ & & & $0.68 * *$ & $0.55-0.86$ \\
\hline Cognitive restructuring & $0.57 * * *$ & $0.47-0.69$ & & & & \\
\hline Support-seeking & 1.12 & $0.95-1.33$ & & & & \\
\hline Avoidance & $3.05 * * *$ & $2.31-4.02$ & & & $1.60 * *$ & $1.14-2.23$ \\
\hline Distraction & 1.03 & $0.86-1.24$ & & & & \\
\hline \multicolumn{7}{|l|}{ Trait anxiety } \\
\hline High versus slight & $56.5 * * *$ & $19.9-161$ & & & $23.7 * * *$ & $7.86-71.7$ \\
\hline Moderate versus slight & $7.66^{* * *}$ & $2.64-22.3$ & & & $4.75 * *$ & $1.57-14.3$ \\
\hline
\end{tabular}

PSS: Perceived Stress Scale; OR: odds ratio; CI: confidence interval.

$* P<0.05 ; * * P<0.01 ; * * * P<0.001$.

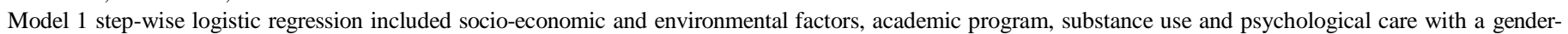

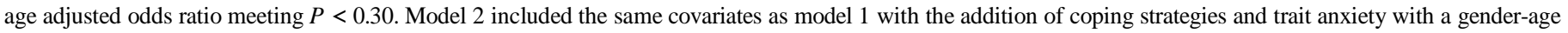
adjusted odds ratio meeting $P<0.30$

Psychological care included tranquillizer, antidepressant or hypnotic use for the last 2 months or consulting a psychologist/psychiatrist since university entrance.

continuous assessment (medicine vs sports or vs dentistry), clerkship (dentistry vs sports or vs medicine). However more medical students had workload as a source of intense stress (medicine vs sports or vs dentistry). Protective problem-solving coping strategies were less developed by dental students (vs sports) and more of them had a high trait anxiety compared with sports students. They used more substances to face stress triggers compared with the other students (Brief Cope substance use scale, median score 4 vs $2,2,2, P<0.001$. This scale is part of avoidance coping strategies).

\section{Discussion}

The study fi aimed at determining whether the academic programs (medicine, dentistry, psychology and sports sciences) are associated with a high level of perceived stress above and beyond other potential predictors, personal and environmental risk factors and coping processes. Only the sports program had a signifi lower perceived stress risk in comparison with medicine after gender-age adjustment. Additional adjustment for socio-economic and non-academic environmental factors, substance use, and psychological care revealed a reduction in the gender-age-adjusted perceived stress risk in sports by $74 \%$ and a signifi tly lower perceived stress risk in psychology compared with medicine. These fi were maintained after additional adjustment for trait anxiety and coping strategies.

The study also aimed at investigating whether academic programs are associated with different coping and vulnerability profiles, focusing on all factors associated with a perceived stress. Compared with sports, medicine or dentistry students, more psychology students had the following stress risk factors: a high trait anxiety, family, personal financial difficulties, anxiety about the future; but they developed much more problem-solving strategies. Compared with sports or psychology, fewer medical and/or dentistry students had personal 
Table 3

Test of indirect effects of academic programs on a perceived stress mediated by coping strategies.

\begin{tabular}{|c|c|c|c|c|c|c|}
\hline Coping strategies & Academic program & Total effect & Direct effect & Indirect effect & Bootstrap 95\% CI & $\begin{array}{l}\text { Comparison between } \\
\text { direct and total effects }\end{array}$ \\
\hline Problem-solving & $\begin{array}{l}\text { Dentistry } \\
\text { Psychology } \\
\text { Sports }\end{array}$ & $\begin{array}{l}-0.3072 \\
-0.9930 \\
-1.2069\end{array}$ & $\begin{array}{l}-0.4712 \\
-0.8864 \\
-1.2645\end{array}$ & $\begin{array}{r}0.1640 \\
-0.1065 \\
0.0576\end{array}$ & $\begin{array}{l}-0.0210 ; 0.4643 \\
-0.2968 ; 0.0344 \\
-0.0932 ; 0.2601\end{array}$ & $\begin{array}{l}\text { NA } \\
12 \% \\
\text { NA }\end{array}$ \\
\hline Avoidance & $\begin{array}{l}\text { Dentistry } \\
\text { Psychology } \\
\text { Sports }\end{array}$ & $\begin{array}{l}-0.3072 \\
-0.9930 \\
-1.2069\end{array}$ & $\begin{array}{l}-0.3870 \\
-0.9349 \\
-1.2325\end{array}$ & $\begin{array}{r}0.0798 \\
-0.0581 \\
0.0256\end{array}$ & $\begin{array}{l}-0.0990 ; 0.3167 \\
-0.2298 ; 0.0723 \\
-0.1192 ; 0.2104\end{array}$ & $\begin{array}{l}\text { NA } \\
6.2 \% \\
\text { NA }\end{array}$ \\
\hline Support-seeking & $\begin{array}{l}\text { Dentistry } \\
\text { Psychology } \\
\text { Sports }\end{array}$ & $\begin{array}{l}-0.3072 \\
-0.9930 \\
-1.2069\end{array}$ & $\begin{array}{l}-0.3063 \\
-0.9937 \\
-1.2061\end{array}$ & $\begin{array}{r}-0.0009 \\
0.0007 \\
-0.0008\end{array}$ & $\begin{array}{l}-0.0927 ; 0.0936 \\
-0.0713 ; 0.0754 \\
-0.0693 ; 0.0915\end{array}$ & $\begin{array}{l}0.3 \% \\
\text { NA } \\
<0.1 \%\end{array}$ \\
\hline Cognitive restructuring & $\begin{array}{l}\text { Dentistry } \\
\text { Psychology } \\
\text { Sports }\end{array}$ & $\begin{array}{l}-0.3072 \\
-0.9930 \\
-1.2069\end{array}$ & $\begin{array}{l}-0.3047 \\
-0.9442 \\
-1.1634\end{array}$ & $\begin{array}{l}-0.0025 \\
-0.0488 \\
-0.0435\end{array}$ & $\begin{array}{l}-0.1185 ; 0.1011 \\
-0.1840 ; 0.0281 \\
-0.1629 ; 0.0404\end{array}$ & $\begin{array}{l}0.8 \% \\
5.2 \% \\
3.7 \%\end{array}$ \\
\hline Distraction & $\begin{array}{l}\text { Dentistry } \\
\text { Psychology } \\
\text { Sports }\end{array}$ & $\begin{array}{l}-0.3072 \\
-0.9930 \\
-1.2069\end{array}$ & $\begin{array}{l}-0.3052 \\
-0.9933 \\
-1.2064\end{array}$ & $\begin{array}{r}-0.0020 \\
0.0003 \\
-0.0005\end{array}$ & $\begin{array}{l}-0.1067 ; 0.1272 \\
-0.0519 ; 0.0681 \\
-0.0507 ; 0.0738\end{array}$ & $\begin{array}{l}0.7 \% \\
\text { NA } \\
<0.1 \%\end{array}$ \\
\hline
\end{tabular}

CI: confidence interval; NA: not applicable

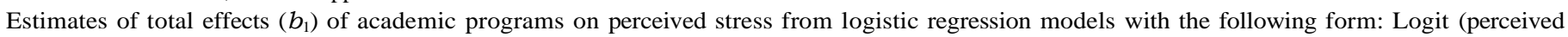

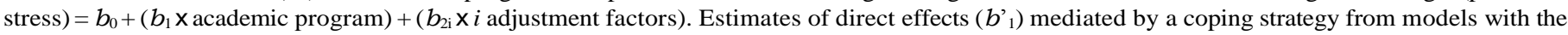

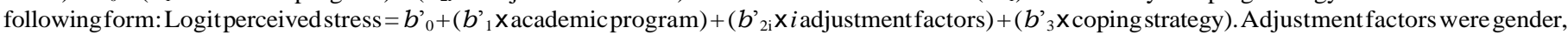

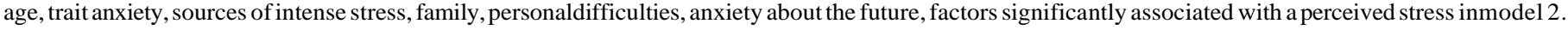

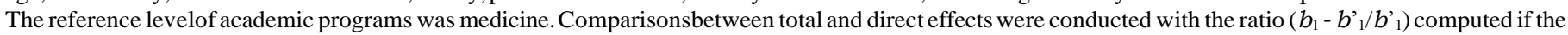
estimate of the direct effect was closer to 0 than the total effect's one [45].

financial difficulties and anxiety about the future but they did not much develop protective problem-solving coping strategies.

The strength of this cross-sectional survey rests on the quality of data. A majority of students participated (55 to $94 \%$ ) and filled in the questionnaires with few missing data $(<5 \%$ for the main endpoint PSS-14). They were representative of their year with respect to gender and age. This contributed to the high quality of the data together with the validated instruments used to measure perceived stress, trait anxiety and coping strategies $[26,28,29,32,33,40]$. In addition, the validated instruments showed good psychometric properties. The survey occurred during mid-term, avoiding interferences with stress due to starting the academic year or final exams. The academic programs provided a large range of stress triggers and coping profiles related to their own demands: entering the hospital wards in medicine, a high selection in dentistry, courses that determined a career in psychology and sports sciences, search for placements in psychology. In addition, medicine and dentistry students were likely to have different profiles compared to students attending other academic courses because of a high selection at the end of the first year. In addition to trait anxiety and coping strategies, collecting demographic data, socio-economic status, stress triggers, substance use and psychological care allowed adjustment for major confounding

Table 4

Distribution of students $[n(\%)]$ who experienced a source of stress as intense for the last 2 months.

\begin{tabular}{|c|c|c|c|c|c|c|}
\hline Sources of stress & Total sample & Faculty Medicine & Faculty Dentistry & Faculty Psychology & Faculty Sports & $P$-value ${ }^{\text {a }}$ \\
\hline \multicolumn{7}{|l|}{ Non-academic } \\
\hline Family & $198(34)$ & $47(32)$ & $23(39)$ & $87(43)$ & $41(24)$ & $<0.001$ \\
\hline Interactions with peers & $141(24)$ & $37(25)$ & $14(24)$ & $54(27)$ & $36(21)$ & 0.61 \\
\hline Love life & $255(44)$ & $58(39)$ & $22(37)$ & $108(54)$ & $67(39)$ & 0.007 \\
\hline Moral isolation & $184(32)$ & $39(27)$ & $20(34)$ & $94(47)$ & $31(18)$ & $<0.001$ \\
\hline Personal financial difficulties & $227(39)$ & $32(21)$ & $18(31)$ & $108(54)$ & $69(40)$ & $<0.001$ \\
\hline Personal health problems & $128(22)$ & $18(12)$ & $11(19)$ & $61(30)$ & $38(22)$ & $<0.001$ \\
\hline Addiction & $72(12)$ & $14(9)$ & $8(14)$ & $32(16)$ & $18(11)$ & 0.24 \\
\hline Anxiety about the future & $338(58)$ & $59(40)$ & $18(31)$ & $163(81)$ & $98(57)$ & $<0.001$ \\
\hline \multicolumn{7}{|l|}{ Academic } \\
\hline Exams & $409(70)$ & $106(71)$ & $41(69)$ & $164(82)$ & $98(57)$ & $<0.001$ \\
\hline Continuous assessment & $293(51)$ & $36(25)$ & $32(54)$ & $150(75)$ & $75(44)$ & $<0.001$ \\
\hline Clerkship or placement & $191(33)$ & $61(41)$ & $1(2)$ & $73(36)$ & $56(33)$ & $<0.001$ \\
\hline Workload & $299(52)$ & $94(63)$ & $24(41)$ & $118(59)$ & $63(37)$ & $<0.001$ \\
\hline
\end{tabular}

\footnotetext{
${ }^{a} P$-values for comparisons between the four academic programs using Pearson $\mathrm{Chi}^{2}$ test.
} 


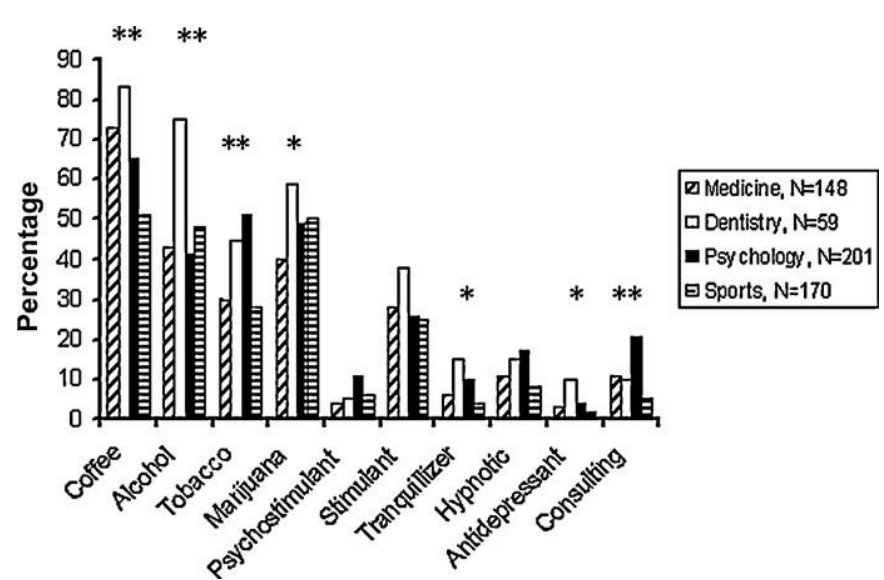

Fig. 1. Substance use during the last 2 months and mental health specialist consulting since university entrance, in third-year undergraduate students. Note. Alcohol: :'. once per week; marijuana: past or current use; stimulant: over-thecounter stimulant; consulting: a psychologist or a psychiatrist since university entrance. Comparison between the four academic domains, $* * P<0.001$; $* P<0.05$.

factors [1], which was technically possible due to a large sample size. Age and gender were adjusted in all models. The 20-year-old threshold for age dichotomisation was chosen to account for a French standard education without repeating a year, avoiding a bias due to multiple previous curricula and heterogeneous maturity.

The present results support the hypothesis that the medicine program has a higher perceived stress risk even after adjusting for personal and non-academic environmental factors and coping strategies compared with psychology and sports programs. They are in line with a report which appraised the psychological distress in freshmen [41]. Possible arguments may be brought in: medicine program is demanding and the third-year French medical program is characterized by the transition to clinical training which is associated with high depression scores [42-44]. In the present study, workload, a strong stress risk factor, was reported by most medical students.

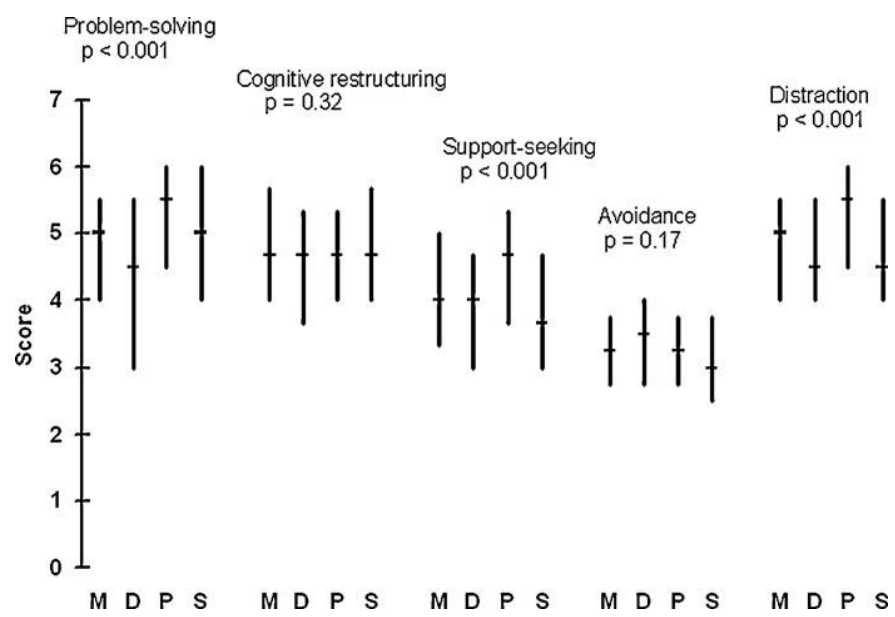

Fig. 2. Higher-order coping dimensions in third-year undergraduate students, median score (interquartile). $P$-value: comparison between the four academic programs, medicine (M), dentistry (D), psychology (P) and sports sciences (S).
We investigated the role of cofactors in the relationship between academic programs and perceived stress. Additional adjustments for socio-economic and non-academic environmental factors, substance use, and psychological care revealed a substantial reduction in the gender-age-adjusted perceived stress risk by $74 \%$ in sports and a significantly lower perceived stress risk in psychology compared with medicine. In the absence of interactions, these results suggest that these additional factors are confounding factors in the relationship between academic programs and perceived stress. This could be explained by the different students' profiles regarding risk factors. Compared with sports or psychology students, fewer medicine students had personal financial difficulties and anxiety about the future.

Although coping strategies are considered as mediators of the relationship between antecedent variables and health [19], no significant indirect effect of academic programs on perceived stress mediated by coping strategies was observed. We tested significance of indirect effects with percentile-based bootstrap confidence intervals as recommended by Preacher and Hayes [38,39]. However, the upper boundary of the $95 \%$ confidence interval of the indirect effect of psychology on perceived stress mediated by problem-solving strategies was close to $0(0.0344$, Table 3$)$. In addition, the relative increase in estimates of the direct effect compared with the total effect (12\%) was above the threshold set by Maldonado and Greenland to define an indirect effect, 10\% [45]. These findings suggest that problem-solving strategies are likely to mediate the protective effect of the psychology program on perceived stress, compared with medicine. This is in line with the psychology program making students aware of adaptive coping strategies. In addition, in the present study psychology students much more developed protective problem-solving coping strategies compared with medical and dental students, although they were more presenting perceived stress risk factors.

The study shows that a high trait anxiety dominated the independent perceived stress risk factors by an order of magnitude, which supports findings about neuroticism-like traits. These latter traits (including trait anxiety) would reflect a greater sensitivity to negative information and are posited as post-traumatic stress disorder and mood disorders risk factors $[46,47]$. Personal financial difficulties were a perceived stress risk factor, which is in agreement with the evidence of low socio-economic status strongly associated with mental disorder [48]. The present study does not confirm a higher perceived stress risk in female students if trait anxiety was adjusted for $[1,3,49,50]$. This may be driven by a high trait anxiety preferentially present among females. Surprisingly, doing regular exercise was not an independent correlate although it is deemed to reduce stress [2]. These independent correlates of perceived stress emphasize the need for adjusting for personal and environmental factors in studies dealing with stress: first, trait personality, then coping strategies and stress triggers $[16,17]$.

As the study was based on the transactional stress and coping model, the interaction between trait anxiety and the students' 
context (i.e., academic programs) was tested. But it failed to be significant. Hence, in students with a high trait anxiety, the academic environment is not likely to act much upon the increase in perceived stress due to trait anxiety [51].

The study presents some limitations. Because the survey was cross-sectional, no causal inferences are implied between situational factors and a perceived stress. This limit specially applies to coping strategies which may evolve with stressful situations and affect perceived stress [19]. The direction of association is unknown. Certain personality and coping profiles may be a determinant in the choice of professions and therefore of academic programs. Different academic programs may in turn lead to varying levels of stress or promote different coping strategies. Secondly, physical activity, economic status, stress triggers, substance use and psychological care were selfreported without validated tools. In addition, regular exercise may have been misunderstood as sports. However the measurement errors likely affected equally all participants. The resulting bias may have not affected much the results. Finally, the survey enrolled undergraduate students in a single city. Since French universities are self-governing, academic setting may differ substantially in other cities, which will hamper direct generalisation of the results. But as a counterpart, recruitment in diverse settings, with or without professional program, i.e. clerkship for medicine, placement for psychology and practical work lab for dentistry, would mitigate this drawback. Participants globally had a similar trait anxiety as the French adult population [28].

The study suggests that academic sources of intense stress may result in students' engagement in dysfunctional coping processes rather than in problem-solving coping strategies. This emphasizes that identifying the major academic stressors is the fi step in improving the academic environment to reduce stress. An effort should then be undertaken to offer students a training in order to develop adaptive coping strategies to prevent the harmful consequences of a high perceived stress level $[8,13,14]$, especially in medicine and dentistry. Active coping, planning, effort expenditure, relaxation, and positive reappraisal constitute a set of effi ient strategies to help improving health, academic involvement and short- and long-term performance [52]. Students who do not cope effi with stress could be especially trained to:

- identify their major academic stressors;

- realize which ineffective coping strategies (such as avoidance through substance use) they use to face these stressors;

- develop a repertoire of adaptive coping responses that might be used instead.

This kind of coping training has been successfully implemented in other contexts [53] and is promising. Mindfulness-Based Stress Reduction (MBSR) techniques, which have been shown to reduce significantly individual reports of perceived stress, worry, and anxiety [54], could also be offered. Education-based practitioners and applied psychologists in stress management are to be resorted to in order to promote academic success and adaptive health-behaviour in students.

In conclusion, sports and psychology programs had a lower perceived stress risk compared with medicine. Personal and environmental risk factors as well as coping strategies modified the association between academic program and perceived stress. Developing adaptive coping strategies in students through empirically driven psycho-educational programs and improving the academic framework would contribute to prevent the deleterious consequences of high perceived stress levels.

\section{Disclosure of interest}

The authors declare that they have no conflicts of interest concerning this article.

\section{Acknowledgements}

We thank all students who participated in the study, those who pilot tested the questionnaire, Anaïs Maneveau, Karine Joullié, Chloé Girod, Héléna Setruk, and Michael Michelini who circulated the questionnaire among sports sciences, dental and medical students. We thank Philippe Mailhé and Sophie Maurin for scanning technical assistance, Anaïs Maneveau, Nora Couderc and Marie Morgane Meunier for their assistance in data entry.

We gratefully acknowledge the contribution of MarieChristine Picot, Claude Terral, Diane Purper-Ouakil, JeanPhilippe Boulenger and Ismaël Conejero for their relevant comments, Cara-Chan Manville and André Neveu for carefully reviewing the English language of this manuscript.

We thank the reviewers for their relevant comments which contributed to improve the manuscript.

We thank the Presidents and Vice-Presidents of the Universities Montpellier-1 and Montpellier-3, the Deans of the Medical School, the Dentistry School and the Sports sciences program, who approved this study.

\section{References}

[1] Abouserie R. Sources and levels of stress in relation to locus of control and self-esteem in university students. Educ Psychol 1994;14(3):323-30.

[2] Hudd SS, Dumlao J, Erdmann-Sager D, Murray D, Phan E, Soukas N, et al. Stress at college: effects on health habits, health status and selfesteem. Coll Stud J 2000;34(2):217-28.

[3] Pierceall EA, Keim MC. Stress and coping strategies among community college students. Commun Coll J Res Pract 2007;31:703-12.

[4] Ladner J, Grigioni S, Villet H, Beaucreux ML, Maillot C, Déchelotte P. Évaluation du stress perçu chez les étudiants en profession de santé. Rev Epidemiol Sante Publique 2008;56(5S):324.

[5] Baily RC, Miller C. Life satisfaction and life demands in college students. Soc Behav Pers 1998;26:51-6.

[6] Dyson R, Renk K. Freshmen adaptation to university life: depressive symptoms, stress, and coping. J Clin Psychol 2006;62(10):1231-44.

[7] Santen SA, Holt DB, Kemp JD, Hemphill RR. Burnout in medical students: examining the prevalence and associated factors. South Med J 2010;103(8):758-63. 
[8] Dyrbye LN, Thomas MR, Shanafelt TD. Systematic review of depression, anxiety, and other indicators of psychological distress among US and Canadian medical students. Acad Med 2006;81(4):354-73.

[9] Beck DL, Hackett MB, Srivastava R, McKim E, Rockwell B. Perceived level and sources of stress in university professional schools. J Nurs Educ 1997;36(4):180-6.

[10] Gupchup G, Borrego M, Konduri N. The impact of student life stress on health related quality of life among doctor of pharmacy students. Coll Stud J 2004;38:292-301.

[11] Marshall LL, Allison A, Nykamp D, Lanke S. Perceived stress and quality of life among doctor of pharmacy students. Am J Pharm Educ 2008;72(6): 137 .

[12] Tavolacci MP, Grigioni S, Villet H, Déchelotte P, Ladner J. Évaluation du stress perçu et comportements à risque chez les étudiants. Rev Epidemiol Sante Publique 2010;58(S2):54.

[13] Compas BE, Connor-Smith JK, Saltzman H, Thomsen AH, Wadsworth ME. Coping with stress during childhood and adolescence: problems, progress, and potential in theory and research. Psychol Bull 2001;127(1): 87-127.

[14] Kaplan D, Liu R, Kaplan H. School related stress in early adolescence and academic performance three years later: the conditional influence of self expectations. Soc Psychol Educ 2005;8(1):3-17.

[15] Misra R, McKean M, West S, Russo T. Academic stress of college students: comparison of student and faculty perceptions. Coll Stud J 2000;34:236-45.

[16] Heins M, Fahey SN, Leiden LI. Perceived stress in medical, law, and graduate students. J Med Educ 1984;59(3):169-79.

[17] Helmers KF, Danoff D, Steinert Y, Leyton M, Young SN. Stress and depressed mood in medical students, law students, and graduate students at McGill University. Acad Med 1997;72(8):708-14.

[18] Folkman S, Moskowitz JT. Coping: pitfalls and promise. Annu Rev Psychol 2004;55:745-74.

[19] Lazarus R, Folkman S. Stress, appraisal and coping. New-York: Springer; 1984.

[20] Dunkley DM, Blankstein KR, Halsall J, Williams M, Winkworth G. The relation between perfectionism and distress: hassles, coping, and perceived social support as mediators and moderators. J Couns Psychol 2000;47(4):437-53.

[21] Sasaki M, Yamasaki K. Stress coping and the adjustment process among university freshmen. Couns Psychol Q 2007;20(1):51-67.

[22] Scheier MF, Carver CS, Bridges MW. Distinguishing optimism from neuroticism (and trait anxiety, self-mastery, and self-esteem): a reevaluation of the Life Orientation Test. J Pers Soc Psychol 1994;67(6):1063-78.

[23] Pritchard ME, Wilson GS, Yamnitz B. What predicts adjustment among college students? A longitudinal panel study. J Am Coll Health 2007; 56(1):15-21.

[24] Endler NS, Parker JDA. Stress and anxiety: conceptual and assessment issues. Stress Med 1990;6:243-8.

[25] Konduri N, Gupchup G, Borrego M, Worley-ouis M. Assessment of the reliability and validity of a stress questionnaire for pharmacy administration graduate students. Coll Stud J 2006;40:78-90.

[26] Cohen S, Kamarck T, Mermelstein R. A global measure of perceived stress. J Health Soc Behav 1983;24(4):385-96.

[27] Gauthier J, Bouchard S. Adaptation canadienne-française de la forme révisée du State-Trait Anxiety Inventory de Spielberger. Can J Behav Sci/ Rev Can Sci Comportement 1993;25(4):559-78.

[28] Bruchon-Schweitzer M, Paulhan I. Manuel inventaire d'anxiété État-Trait Forme Y (STAI-Y). Paris: ECPA; 1993.

[29] Bruchon-Schweitzer M. Psychologie de la santé : modèles, concepts et méthodes. Paris: Dunod; 2002.

[30] Ross SE, Neibling BC, Heckert TM. Sources of stress among college students. Coll Stud J 1999;33(22):312-7.

[31] de Anda D, Baroni S, Boskin L, Buchwald L, Morgan J, Ow J, et al. Stress, stressors and coping among high school students. Child Youth Serv Rev 2000;22(6):441-63.
[32] Carver CS. You want to measure coping but your protocol's too long: consider the brief COPE. Int J Behav Med 1997;4(1):92-100.

[33] Muller L, Spitz E. Multidimensional assessment of coping: validation of the BriefCOPE among French population. Encephale 2003;29(6):507-18.

[34] Bachman JG, Staff J, O’Malley PM, Schulenberg JE, Freedman-Doan P. Twelfth-grade student work intensity linked to later educational attainment and substance use: new longitudinal evidence. Dev Psychol 2011;47(2):344-63.

[35] Serras A, Saules KK, Cranford JA, Eisenberg D. Self-injury, substance use, and associated risk factors in a multi-campus probability sample of college students. Psychol Addict Behav 2010;24(1):119-28.

[36] Lynch JW, Kaplan GA, Cohen RD, Tuomilehto J, Salonen JT. Do cardiovascular risk factors explain the relation between socioeconomic status, risk of all-cause mortality, cardiovascular mortality, and acute myocardial infarction? Am J Epidemiol 1996;144(10):934-42.

[37] MacKinnon DP, Krull JL, Lockwood CM. Equivalence of the mediation, confounding and suppression effect. Prev Sci 2000;1(4):173-81.

[38] Preacher KJ, Hayes AF. SPSS and SAS procedures for estimating indirect effects in simple mediation models. Behav Res Methods Instrum Comput 2004;36(4):717-31.

[39] Hayes A. Beyond Baron and Kenny: statistical mediation analysis in the new millennium. Commun Monogr 2009;76(4):408-20.

[40] Spielberger CD, Vagg PR, Barker LR, Donham GW, Westberry LG. The factor structure of the State-Trait Anxiety Inventory. In: Spielberger IGS, editor. Stress and anxiety. New-York: Hemisphere/Wiley; 1980.

[41] Verger P, Combes JB, Kovess-Masfety V, Choquet M, Guagliardo V, Rouillon F, et al. Psychological distress in first year university students: socioeconomic and academic stressors, mastery and social support in young men and women. Soc Psychiatry Psychiatr Epidemiol 2009;44(8): 643-50.

[42] Compton MT, Carrera J, Frank E. Stress and depressive symptoms/ dysphoria among US medical students: results from a large, nationally representative survey. J Nerv Ment Dis 2008;196(12):891-7.

[43] Rosal MC, Ockene IS, Ockene JK, Barrett SV, Ma Y, Hebert JR. A longitudinal study of students' depression at one medical school. Acad Med 1997;72(6):542-6.

[44] Godefrooij MB, Diemers AD, Scherpbier AJ. Students' perceptions about the transition to the clinical phase of a medical curriculum with preclinical patient contacts; a focus group study. BMC Med Educ 2010;10:28.

[45] Maldonado G, Greenland S. Simulation study of confounder-selection strategies. Am J Epidemiol 1993;138(11):923-36.

[46] Schnurr P, Vielhauer M. Personality as a risk factor for PTSD. In: R Y, editor. Risk factors for posttraumatic stress disorder. Washington, DC: American Psychiatric Press; 1999.

[47] Trouillet R, Gana K. Age differences in temperament, character and depressive mood: a cross-sectional study. Clin Psychol Psychother 2008;15(4):266-75.

[48] Patel V, Flisher AJ, Hetrick S, McGorry P. Mental health of young people: a global public-health challenge. Lancet 2007;369(9569):1302-13.

[49] Brougham RR, Zail CM, Mendoza CM, Miller JR. Stress, sex differences, and coping strategies among college students. Curr Psychol 2009;28:8597.

[50] Dusselier L, Dunn B, Wang Y, Shelley 2nd MC, Whalen DF. Personal, health, academic, and environmental predictors of stress for residence hall students. J Am Coll Health 2005;54(1):15-24.

[51] Boyes M, French D. Neuroticism, stress, and coping in the context of an anagram-solving task. Pers Individ Differences 2010;49:380-5.

[52] Thompson A, Gaudreau P. From optimism and pessimism to coping: the mediating role of academic motivation. Int J Stress Manage 2008;15(3): 269-88.

[53] Meichenbaum D, Jaremko M. Stress rduction and prevention. New-York: Plenum Press; 1983.

[54] Shapiro SL, Schwartz GE, Bonner G. Effects of mindfulness-based stress reduction on medical and premedical students. J Behav Med 1998; 21(6):581-99. 